\author{
Military Technical College \\ Kobry El-Kobbah, \\ Cairo, Egypt
}

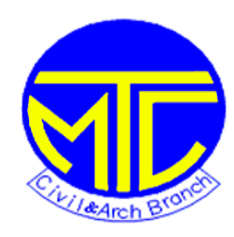

\author{
$8^{\text {th }}$ International Conference \\ on Civil and Architecture \\ Engineering \\ ICCAE-8-2010
}

\title{
Blast Mitigation using Polyurethane Foam to Retrofit Fortified Sandwich Structures
}

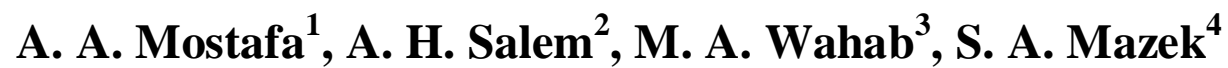

\begin{abstract}
Development of weapons has increased over the last decade. The explosives are optimized to produce heat and pressure effects. Fortified structures need to be protected from blast wave impact. Armoured doors are used at the fortified structure in order to protect people, weapons, and ammunition from blast waves. Fireball and blast hit a sandwich armoured door which could be damaged by blast wave.

In the present study, the prediction of the sandwich armed steel doors performance under the impact of the blast wave effect is highlighted. 3-D model is proposed to study polyurethane foam (RPF) layer to retrofit the sandwich armed steel doors using a 3-D finite element analysis. Hexagonal core sandwich door and stiffener channel sandwich door are used so as to study blast mitigation using the RPF layer. The study presents a comparison between the field test and the finite element analysis to assess the accuracy of the proposed finite element model. The constitutive model for this analysis contains elasto-plastic materials. An elasto-plastic model is employed to represent the armoured doors, the concrete wall of the fortified structure, and the RPF layer. The proposed model is programmed and linked to an available computer program Autodyn3D (2005).

The finite element model takes into account the effects of the blast load, the connection between the armoured doors and the frame fixed to the concrete wall, and RPF layer. The effects are expressed in terms of the displacement-time history of the sandwich armed doors and the pressuretime history effect on the sandwich armoured doors as the explosive wave propagates. A parametric study based on the 3-D nonlinear finite element
\end{abstract}

\footnotetext{
${ }^{1} \mathrm{Ph}$. D. student, Civil Engineering Department, Military Technical College, Cairo, Egypt.

${ }^{2}$ Professor, Civil Engineering Department, Faculty of Engineering, Ain Shams University, Cairo.

${ }^{3}$ Ph. D. Lecturer, Civil Engineering Department, Military Technical College, Cairo, Egypt.

${ }^{4}$ Assistance Professor. Civil Engineering Department, Military Technical College, Cairo, Egypt.
} 
analysis is conducted to study the impact of the RPF layer on the sandwich armed steel door performance. The behavior of the sandwich armoured door of the armoured doors is investigated and presented under the blast waves obtained from detonating 1-kg, 2-kg, and 3-kg TNT at scaled distance of $1 \mathrm{~m}$.

\section{Keywords}

Displacements, finite element analysis, blast wave, sandwich structures, armoured door.

\section{Introduction}

Current codes and regulations to estimate stress wave intensities owing to outdoor blasting at the entrance of the fortified structure are usually based on some empirical methods due to the extreme complexities of the phenomena of the process in blasting effect (Aimone, 1982; Liu and Katsabanis, 1997; Fayad, 2009; Mohamad, 2006; Schueller, 1991; Zhang and Valliappan, 1990). These empirical methods were obtained from observations and measurements in field blast tests. The empirical methods tended to overlook the physical laws governing the process in blasting effect (Beshara, 1994; Smith and Hetherington, 1994). Different countries and group of countries apply different design manuals (NATO, 1977; Gustafsson, 1973; Liu and Katsabanis, 1997; Technical Manual TM 5-8851, 1986; Technical Manual TM 5-1300, 2008 ).

Since armoured doors damage and stress wave propagation are highly dependent on material properties, data obtained from one site might not be directly used to another site. It is very expensive to conduct field blast tests in every site and sometimes it is impossible to carry out such field tests due to the safety and the environmental constraints (Hao et al., 1998). Thus, a reliable numerical model validated against field measured data is a costeffective means of examining the highly dynamic and nonlinear process of blast-induced stress wave propagation in engineering (Hao et al., 1998).

In this study, the field blast tests are conducted to verify a proposed numerical model to understand armoured sandwich door performance at the entrance of the fortified structure. The polyurethane foam (RPF) layer is also studied using a 3-D finite element analysis. The RPF is considered as a mitigation system to protect the armoured steel door against blast impact. Developing such a numerical method has always been a challenge due to the complicated properties of blasting process and highly nonlinear and strain rate dependent dynamic responses (Hao et al., 1998; Smith and Hetherington, 1994). It needs to properly model the explosion process effect on the armoured sandwich doors behavior. 
Fireball and blast can travel in free air to hit the armoured sandwich steel door, as shown in Fig. 1. However, hexagonal core sandwich door (XCS) and channel stiffener sandwich door (CSS) are developed and studied to discuss the effect of the RPF layer covering the front of the sandwich armoured steel doors to retrofit them, as shown in Fig. 2. The XSC door and the CSS door are the most famous armoured doors used to protect the fortified structure (Fayad, 2009; Mohamad, 2006). In this study, the performance of the armoured door with the different internal core structure systems is studied with and without using the RPF. However, the two internal core structure systems of the armoured door are shown in Fig. 2. The dimension for each hexagonal tube (1 mm thickness) of this internal core structure system in the armoured doors is shown in Fig. 2. The dimension for each channel stiffener ( $2 \mathrm{~mm}$ thickness) of this internal core structure system in the armoured doors is also shown in Fig. 2. In addition, the outer covers of the armoured door are steel plates. The steel plate is rectangular in shape of $2.2 \mathrm{~m}$ height, $2.0 \mathrm{~m}$ width, and $6 \mathrm{~mm}$ thickness. The interior spacing (core spacing) between the outer steel plates covering the armoured door is $10 \mathrm{~cm}$.

The blast mitigation of the armoured door becomes a conflict for engineer designers to protect people and weapons inside the fortified structure. The armoured doors need more engineering insight to understand the performance of the mitigation system under the impact of the blast wave propagation. The polyurethane foam (RPF) layer is used in this study as the blast mitigation system. The thickness of the RPF layer covering the armoured door is $10 \mathrm{~cm}$ with the same core spacing of the armoured door, as shown in Fig. 3.

The study presents a comparison between the empirical method developed by Henrych (Beshara, 1994) and the finite element analysis to calculate the pressure- time history hit the armoured doors. This study is also extended to assess the accuracy of the proposed finite element model. The study also presents a comparison between the field study conducted by us and the finite element analysis to assess the accuracy of the proposed finite element model. The constitutive model for this analysis contains elasto-plastic materials. A modified Drucker-Prager model is used to model the rock media. An elasto-plastic model is also employed to represent the armoured doors, the concrete wall of the structure performance, and the RPF layer.

The armoured door model with and without the RPF is implemented in a finite element code Autodyn3D (2005). Numerical results obtained by the finite element analysis are compared with the data obtained by the field data. It shows that the model can well predict the blasting-induced pressure on the armoured doors. Numerically simulated peak particle displacement- 
time history of the different armoured doors using the RPF will be calculated and presented. The study will show the impact of the RPF on the performance of the different armoured doors based on the response of each door.

\section{Numerical Model}

In numerical modeling, air and equivalent explosive TNT are simulated by Euler processor, as shown in Fig. 3. The air and the equivalent explosive TNT are assumed to satisfy the equation of state (EOS) of ideal gas (Hao et al., 1998). Rock media, reinforced concrete wall (RC) of the fortified structure, and RPF layer are modeled by the modified isotopic damage model and simulated by Lagrange processor (Hao et al., 1998; Wu et al., 1999), as shown in Fig. 3. The whole domain, including the rock media, the air media, the RC wall, the RPF layer, the armoured door, and TNT explosive, is assumed to be symmetric in the $\mathrm{X}, \mathrm{Y}, \mathrm{Z}$ directions, as shown in Fig. 4. Transmitting boundary is used to reduce reflection of stress wave from the numerical boundaries. The material constants of the rock mass obtained from site investigation are used in numerical simulation, while standard constants of air, TNT, and the RPF layer are from the Autodyn3D material library. These include Poisson's ratio of the rock media $v=0.16$; averaged mass density of rock media $2600 \mathrm{~kg} / \mathrm{m}^{3}$; air mass density $\rho=1.225 \mathrm{~kg} / \mathrm{m}^{3}$; and yield strength of rock $\mathrm{f}_{\mathrm{y}}=390 \mathrm{~kg} / \mathrm{cm}^{2}$; bulk modulus of rock $E_{i}=260 \mathrm{t} / \mathrm{cm}^{2}$; air initial internal energy $E n=2.068 \times 10^{5} \mathrm{~kJ} / \mathrm{kg}$; and ideal air constant $\gamma=1.4$. The shear modulus of the rock mass depends on the elastic modulus $E_{i}$ and Poisson's ratio $v$. It should also be noted that viscous damping effect is neglected in the numerical simulation as its influence on high velocity explosion-type responses is insignificant (Hao et al., 1998; Wu et al., 1999).

Shell element is used to model both the membrane (in-plane) and the bending (out-of-plane) behavior of the armoured doors including the internal core structure system, as shown in Figs. 3 and 4. In this study, the fortified structure including the armoured doors with and without the RPF layer is modeled. The boundary condition applied to the armoured door is defined from tow latches and tow hinges, as shown in Fig. 5. The dimension of the armoured door is also shown in Fig. 5. A 4-node rectangular shell element is used for modeling the armoured door with each node having 6 degrees of freedom (three translation and three rotations).

The solid element is also used to model the behavior of the rock media, the concrete structure, the RPF layer, and the air media. The solid element is chosen since it possesses in-plane and out-of-plane stiffness. The solid 
element allows for both in-plane and out-of-plane loads. The solid element is cubic in shape and has 8 nodes with each node having 3 degrees of freedom (three translations).

The mechanical properties of concrete are Poisson's ratio $v=0.18$; averaged mass density of concrete $2520 \mathrm{~kg} / \mathrm{m}^{3}$; elastic modulus $\mathrm{E}=220 \mathrm{t} / \mathrm{cm}^{2}$; compressive strength $\mathrm{f}_{\mathrm{n}}=500 \mathrm{~kg} / \mathrm{cm}^{2}$; and strain to failure of concrete $\varepsilon_{\mathrm{f}}=$ 0.001 . The shear modulus of the concrete mass depends on the elastic modulus E and Poisson's ratio $v$.

The mechanical properties of steel door are Poisson's ratio $v=0.3$; averaged mass density of steel $7900 \mathrm{~kg} / \mathrm{m}^{3}$; elastic modulus $\mathrm{E}=2350 \mathrm{t} / \mathrm{cm}^{2}$; and yield strength $\mathrm{f}_{\mathrm{y}}=3500 \mathrm{~kg} / \mathrm{cm}^{2}$. The shear modulus of the steel depends on the elastic modulus E and Poisson's ratio $v$.

The mechanical properties of the RPF layer are Poisson's ratio $v=0.3$; averaged mass density of RPF layer $1265 \mathrm{~kg} / \mathrm{m}^{3}$; bulk modulus of RPF $E_{i}=$ $20 \mathrm{t} / \mathrm{cm}^{2}$; and yield strength $\mathrm{f}_{\mathrm{y}}=350 \mathrm{~kg} / \mathrm{cm}^{2}$. The shear modulus of the steel depends on the elastic modulus E and Poisson's ratio $v$.

The cubic solid element and the rectangular shell element interface are used between the rock media, the concrete wall of the structures, the RPF layer, the air media, and the armoured door to ensure the compatibility conditions at the interface surface between them as well as the associated stress and strains along the interface surface. This type of finite element is used to link adjacent nodes characterized by stiffness components.

\section{Numerical Model Verification}

The shock of the blast wave is generated when the surrounding atmosphere is subjected to an extreme compressive pulse radiating outward from the centre of explosion. The pressure-time history of a blast wave can be illustrated with a general shape, as shown in Fig. 6 (Gaissmaire, 2003). The illustration is an idealization for an explosion in free air, as shown in Fig. 6. Transient pressure being greater than ambient pressure is defined as the overpressure $\left(\mathrm{P}_{\mathrm{s}}\right)$ (Smith and Hetherington, 1994). The peak overpressure $\left(\mathrm{P}_{\mathrm{s}}\right)$ is the maximum value of the overpressure at a given location. The rise time to peak overpressure will be less than microsecond (Baker et al., 1983).

The study presents a comparison between the pressure-time history obtained by the empirical method (EM) developed by Henrych (Beshara, 1994), by the field blast test, and by the finite element analysis (FEA). The EM method uses the scaled distance $(Z)$ equation (Equation 1) to calculate the peak overpressure (Beshara, 1994). 


$$
Z=\frac{R}{\sqrt[3]{W}}
$$

Where; $\mathrm{R}$ is the distance from the centre of the explosion to a given location in meter and $\mathrm{W}$ is the weight of the explosive in $\mathrm{kg}$.

The equations developed by Henrych (Beshara, 1994) divide the analysis into three fields based on one-meter scaled distances $(Z)$ as presented in equations 2 to 4 .

$$
\begin{array}{ll}
P_{s}=\frac{14.072}{Z}+\frac{5.540}{Z^{2}}-\frac{0.357}{Z^{3}}+\frac{0.00625}{Z^{4}}(\text { bar }) & (\text { for } 0.05<\mathrm{Z}<0.3) \\
P_{s}=\frac{6.194}{Z}-\frac{0.326}{Z^{2}}+\frac{2.132}{Z^{3}}(\text { bar }) & (\text { for } 0.3<\mathrm{Z}<1) \\
P_{s}=\frac{0.662}{Z}+\frac{4.05}{Z^{2}}+\frac{3.288}{Z^{3}}(\text { bar }) & (\text { for } 1<\mathrm{Z}<10)
\end{array}
$$

The scaled distance $(\mathrm{Z})$ is also used to determine the positive duration time $\left(\mathrm{T}_{\mathrm{s}}\right)$ and the positive impulse $\left(\mathrm{i}_{\mathrm{s}}\right)$ by using Fig. 7 (Smith and Hetherington, 1994).

This study is also extended to assess the accuracy of the proposed finite element model. One-kg TNT, two-kg TNT, and three-kg TNT are applied at scaled distance of one meter to obtain the pressure-time history hit the armoured door by the EM, the FEA, and the field blast test at points 1 and 2 (Fig. 7), as shown in Figs. 8 to 10. The result shows that the readings obtained by the field blast test agree well with those estimated by the FEA and the EM. The trend of the pressure-time history hit the armoured door obtained by both the field measurements and the FEA is the same trend as this presented by Gaissmaire (2003), as shown in Figs. 6, 8, 9, and 10.

\section{Impact of Blast Load on Armoured Door Performance with and without RPF Layer}

The displacement-time history of the armoured doors with hexagonal core sandwich door (XCS) and channel stiffener sandwich door (CSS) due to blasting load is calculated using the proposed finite element model. The blast load affects at the entrance of the fortified structure. The finite element model is also used to calculate the displacement-time history of the armoured doors with the RPF layer as mitigation system. The study discusses the impact of the RPF layer on the armoured door performance under the blast impact.

Four cases of the armoured door with and without the RPF layer are studied at the entrance of the fortified structure. At the first case, the XCS door is modeled without using the RPF layer. At the second case, the CSS door is 
modeled without using the RPF layer. At the third case, the XCS door is modeled with using the RPF layer. At the fourth case, the CSS door is modeled with using the RPF layer.

One-kg TNT explosive is used to discuss the impact of the RPF layer on the armoured doors with hexagonal core sandwich (XCS) and with channel stiffener sandwich (CSS) at points 1 and 2 (Fig. 5). The TNT explosive is located at the entrance of the fortified structure within one-meter scaled distance, as shown in Fig. 3. The pressure- time history hit the armoured door is presented in Fig. 11. The trend of the pressure-time history hit the armoured door is the same trend as this presented by Gaissmaire (2003), as shown in Fig 6. The displacement-time history profiles at points 1 and 2 at the armoured XCS doors and the armoured CSS doors for the four cases (Fig. 3) are calculated to discuss the impact of the RPF layer. Figure 12 shows the comparison between the displacement-time history results at point 1 for each case. Figure 13 also presents the comparison between the displacement-time history results at point 2 for each case. The comparison indicates that the response of the armoured door covered by the RPF layer is the smallest response with respect to the response of the armoured door without the RPF layer.

Tow-kg TNT explosive is also used to discuss the impact of the RPF layer on the armoured doors with hexagonal core sandwich (XCS) and channel stiffener sandwich (CSS) at points 1 and 2 (Fig. 5). The pressure- time history hit the armoured door is also presented in Fig. 13. The trend of the pressure-time history hit the armoured door is also the same trend as this presented by Gaissmaire (2003), as shown in Fig 6. The displacement-time history profiles at points 1 and 2 at the armoured XCS doors and the armoured CSS doors for the four cases (Fig. 3) are calculated to discuss the impact of the RPF layer. Figure 15 shows the comparison between the displacement-time history results at point 1 for each case. Figure 16 also presents the comparison between the displacement-time history results at point 2 for each case. The comparison indicates that the response of the armoured door covered by the RPF layer is the smallest response with respect to the response of the armoured door without the RPF layer.

Three-kg TNT explosive is used to discuss the impact of the RPF layer on the armoured doors with hexagonal core sandwich (XCS) and channel stiffener sandwich (CSS) at points 1 and 2 (Fig. 5). The results also show that the response of the armoured door covered by the RPF layer is again the smallest response with respect to the response of the armoured door without the RPF layer as shown in Figs 17,18 .

The difference between the performance of the armoured doors with and without the RPF layer lies in the use of the RPF layer. The XCS and the 
CSS armoured doors (Fig. 2) are used to discuss the impact of the RPF layer on the performance of the doors. Therefore, the finite element analysis gives a better estimation of the response of the armoured door with and without the RPF layer. In general, the armoured doors play an important role to resist the blast load. At the case of the armoured door with the RPF layer gives the smallest displacement readings. Therefore, the RPF layer increases the armoured door stiffness and then reduces the deformation of the armoured door comparing to the armoured door without the RPF layer. Finally, the performance of the armoured doors is highly dependent on material properties as the RPF layer is used as a mitigation system.

\section{Conclusions}

A 3-D nonlinear finite element analysis has been used to predict the performance of the armoured steel door with and without the PRF layer under the blast effect. In this study, the performance of the armoured door with and without the RPF layer is modeled and analyzed using nonlinear finite element computer program Autodyn3D (2005). The following conclusions can be drawn regarding the performance of the armoured door with and without the RPF layer under the impact of the explosive at the entrance of the fortified structure.

- Based on the field blast test and the empirical method developed by Henrych, the 3-D finite element analysis gives a better estimate of the pressure-time history hit the armoured steel door.

- The pressure-time history calculated by the finite element analysis is in reasonable agreement with this obtained by the empirical method developed by Henrych (Beshara, 1994).

- The 3-D finite element model can be successfully used to analyze and estimate the performance of the steel armoured door with and without the RPF layer.

- The pressure-time history profile of the armoured door calculated by the finite element analysis has the same trend as that presented by Gaissmaire (2003).

- The response of the armoured steel door with the RPF layer gives the smallest response with respect to the armoured steel door without the RPF layer.

However, the polyurethane foam (RPF) layer to retrofit the sandwich armed steel doors is an effective tool to resist the blast wave propagation. 


\section{References}

- Aimone, C. T. 1982. Three-Dimensional Wave Propagation Model of Full-Scale Rock Fragmentation. Ph.D. Thesis, Northwestern University, 1982.

- AUTODYN, "Theory Manuals", Version 6.1, Century Dynamics Inc., Sam Ramon, USA, 2005.

- Baker, W. E., Cox, P. A., Kulesz, J. J. and Strehlow, R. A. 1983. Explosion Hazards and Evaluation, Elsevier.

- Beshara, F.B.A. 1994. Modeling of blast loading on aboveground structures -I. Internal blast and ground shock, Comp. \& Structure Vol. 51, No.5.

- Fayad, H. M. 2009. The Optimum Design of the Tunnels Armored Doors under Blast Effects. Ph. D. thesis. Military Technical College (MTC). Cairo

- Gaissmaier, A. E. W. 2003. Aspects of thermobaric weapon. ADF Health, Vol. 4, pp. 3-6.

- Gustafsson, R. 1973. Swedish Blasting Technique. Gothenburg, Sweden, SPI.

- Hao, H., Ma, G. W. and Zhou, Y. X. 1998. Numerical Simulation of Underground Explosions. Fragblast the Int. J. of Blasting and

Fragmentation, 2, pp. 383-395.

- Liu, L. and Katsabanis, P. D. 1997. Development of a Continuum Damage Model for Blasting Analysis. Int. J. Rock Mech. Min. Sci., 34, pp. 217-231.

- Mohamad, L. S. 2006. Study and design of fortified structures due to blast effects. M. Sc thesis. Military Technical College (MTC). Cairo.

- NATO. 1997. Manual on NATO Safety Principles for the Storage of Ammunition and Explosives. In document: AC/258-D/258, Brussels, Belgium.

- Technical Manual TM 5-885-1. 1986. Fundamentals of Protective Design for Conventional Weapons. Headquarters Department of the Army, Washington DC.

- Schueller, C. T. 1991. Structural Dynamics. Springer-Verlag, Berlin, New York, ISBN 0-387-53593-4.

- Smith P. D. \& Hetherington J.G. 1994. Blast and ballistic loading of structures. Butterworth-Heinemann Ltd. UK.

- Wu, C., Hao, H. and Zhou, Y. X. 1999. Dynamic Response Analysis of Rock Mass with Stochastic Properties Subjected to Explosive Loads. Fragblast the International J. Blasting and Fragmentation, 3, pp. 137-153. 
- Zhang, W. and Valliappan, S. 1990. Analysis of Random Anisotropic Damage Mechanics Problems of Rock Mass, Part II: Statistical Estimation. Rock Mechanics and Rock Engineering, 23, pp. 241-259.

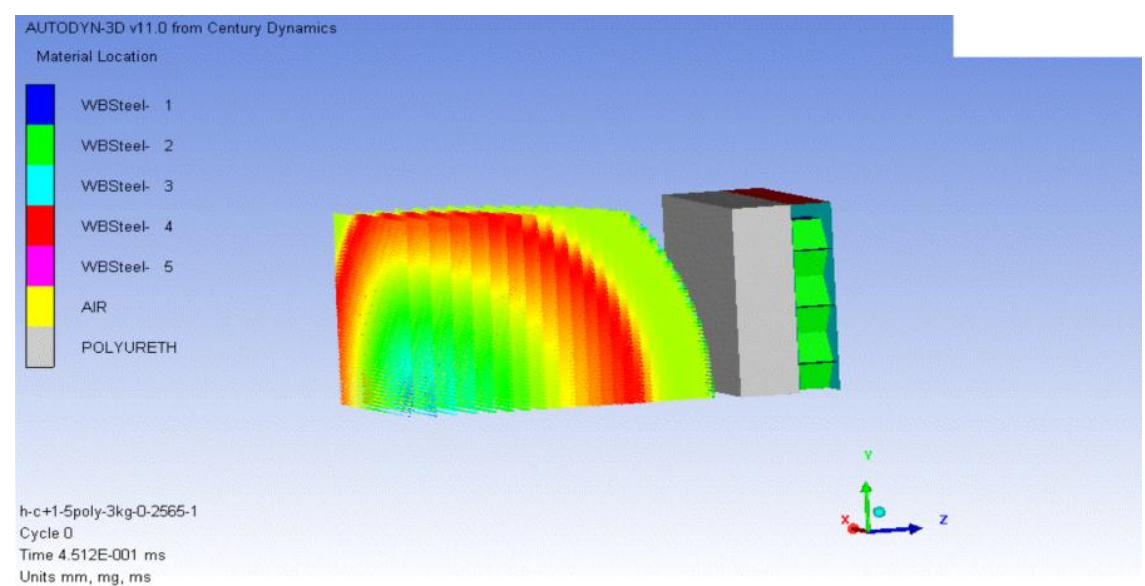

Fig. 1: Blast wave propagation hit armoured sandwich door

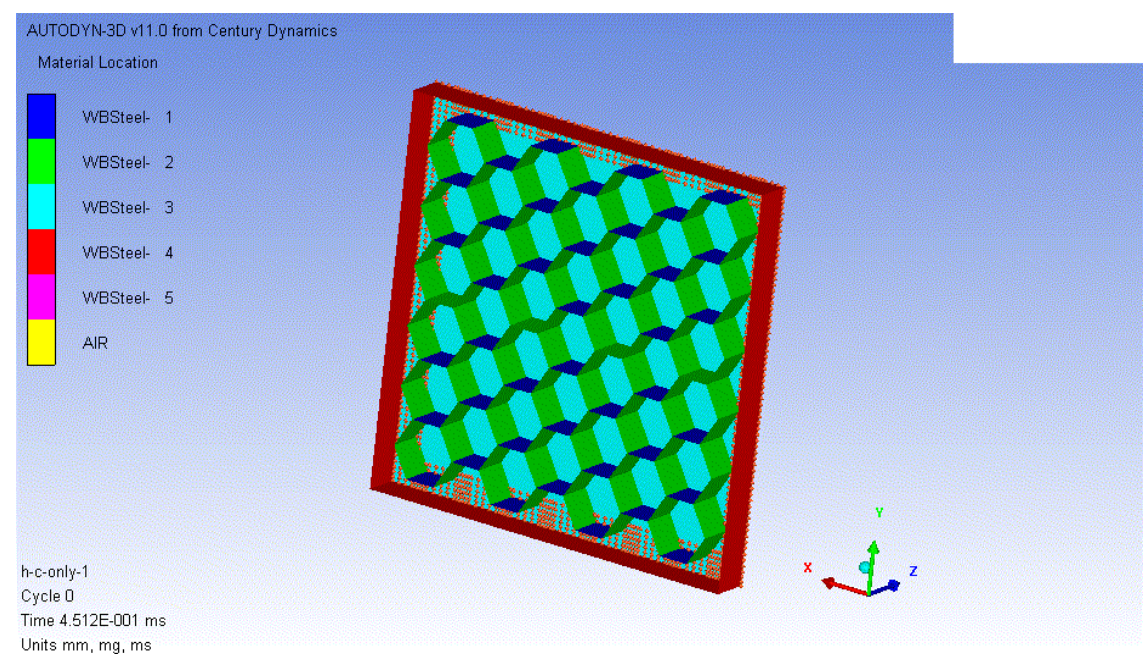

Hexagonal core sandwich door (XCS) (hexagonal tube) 


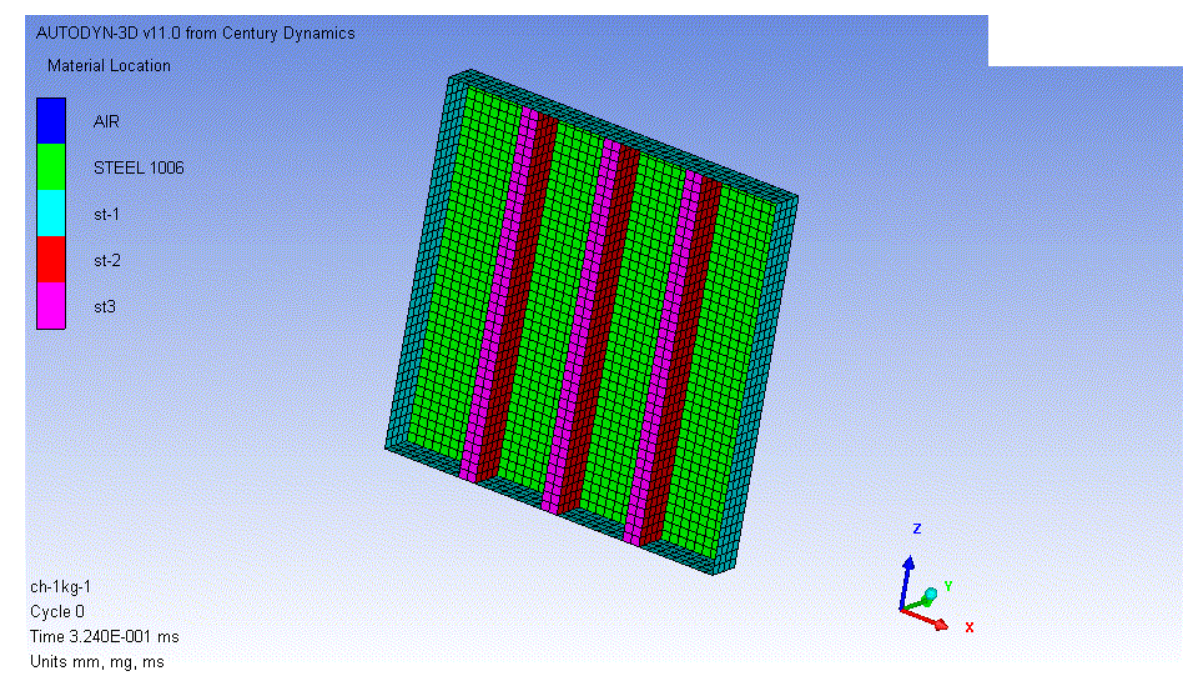

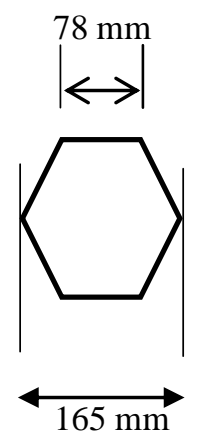

Cross section on each hexagonal tube (1 mm thickness)
Channel stiffener sandwich door (CSS)

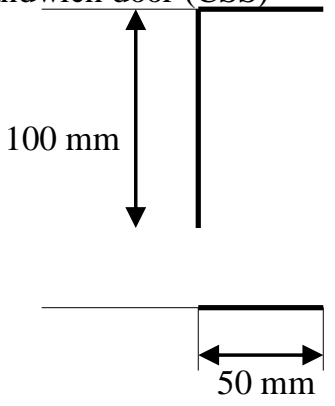

Cross section on each channel stiffener ( $2 \mathrm{~mm}$ thickness)

Fig. 2: Developed different internal core structure systems of steel

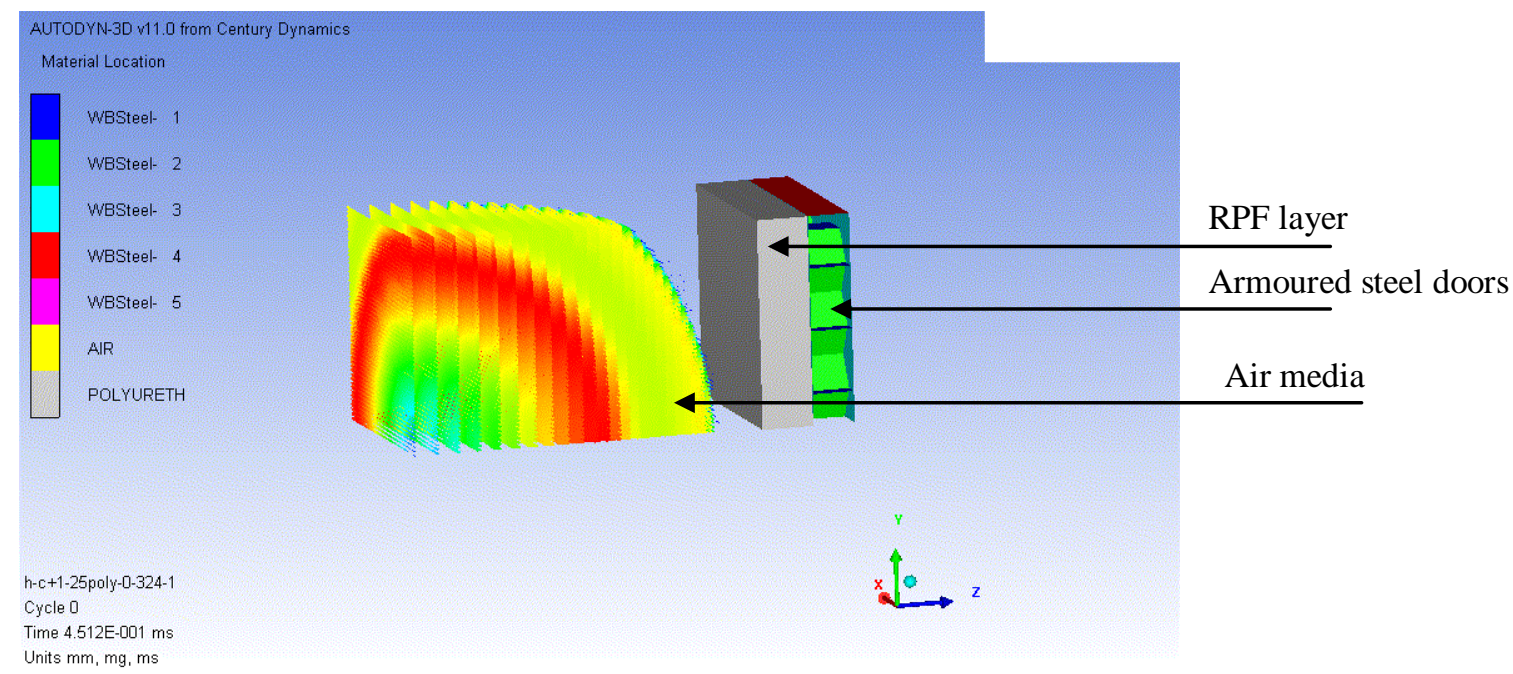

Fig. 3: 3-D finite element model of the armoured doors with 


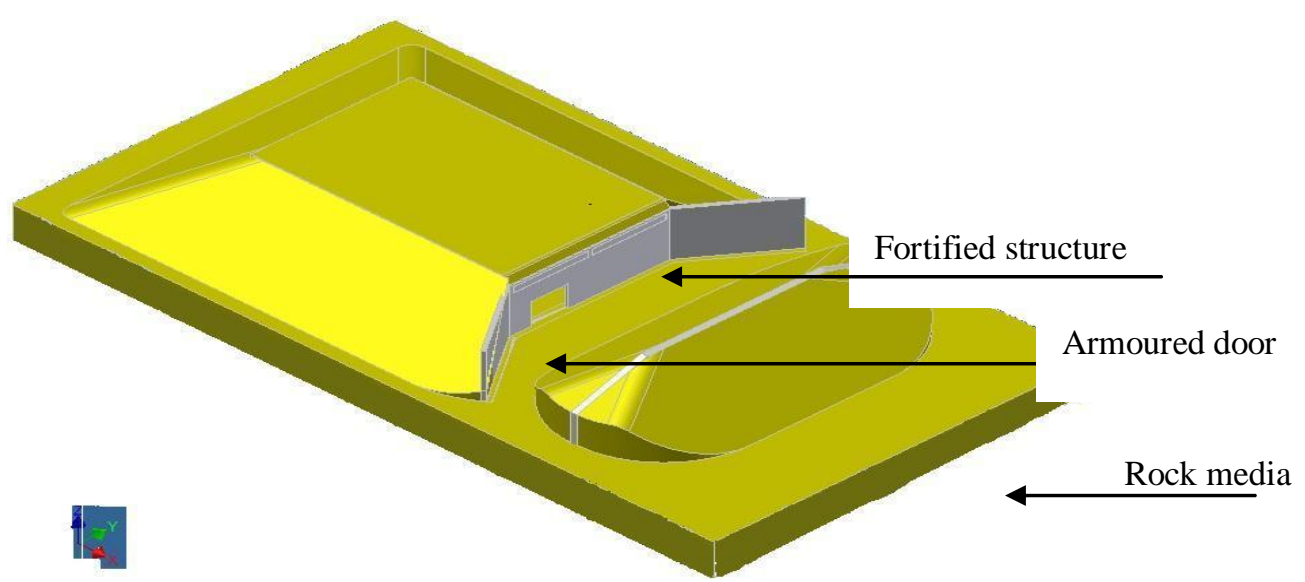

Fig. 4: Numerical model shows section elevation of RC walls, rock media, and steel armoured door

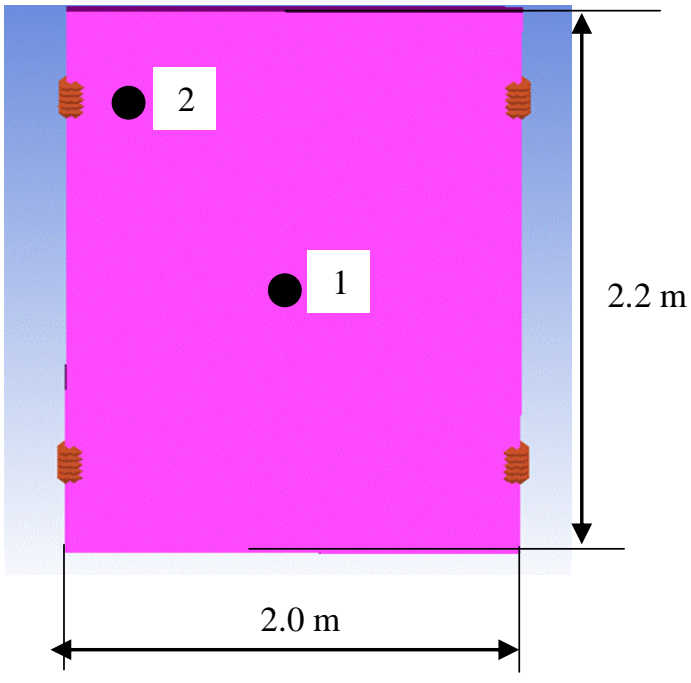

Fig. 5: Numerical model shows the boundary condition of door and location of

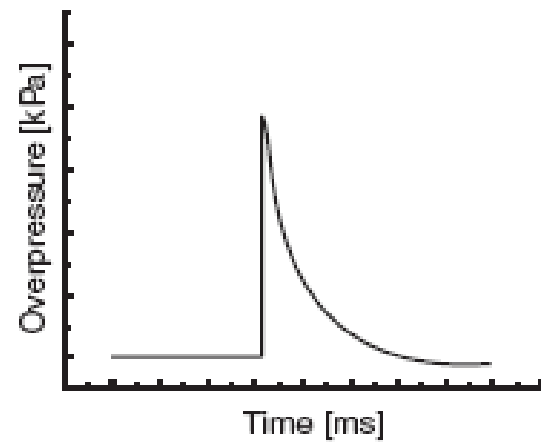

Fig. 6: Typical pressure time history in open air 


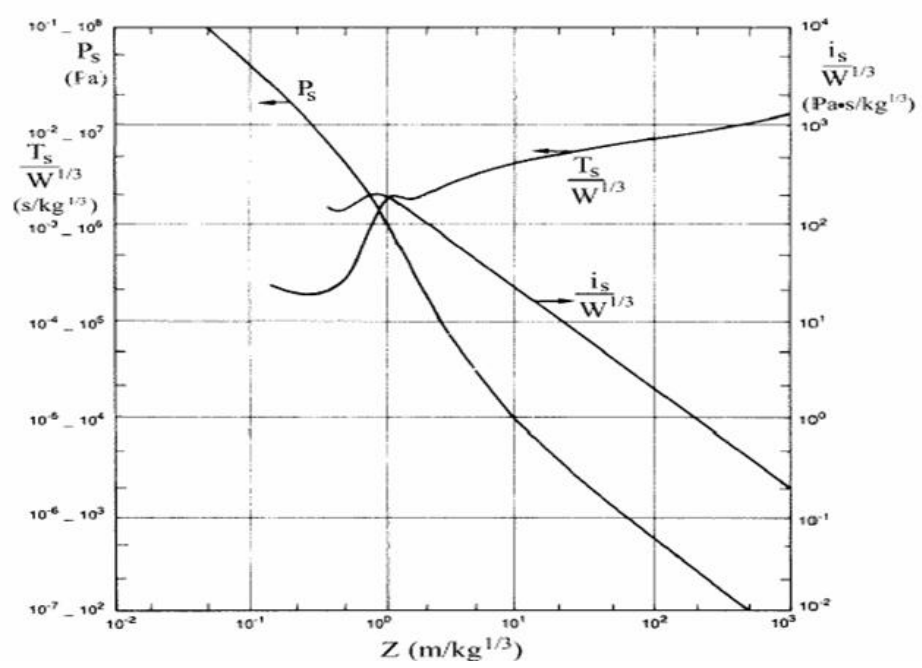

Fig. 7: Blast wave parameters for spherical charges of TNT (Smith and

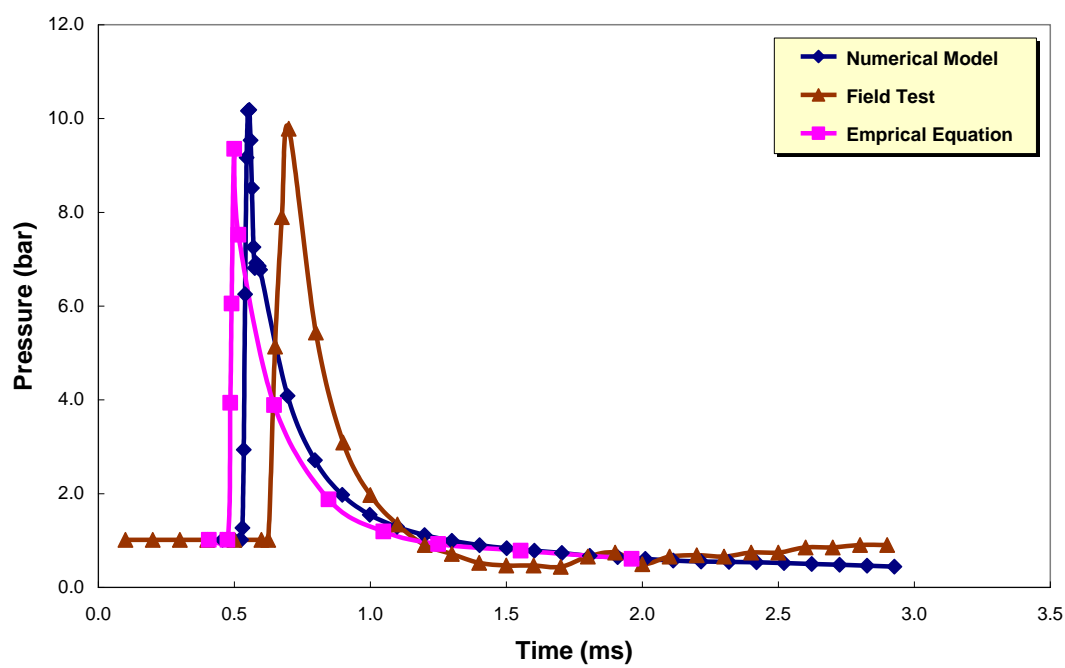

Fig. 8: Pressure-time history at point 1 for $1-\mathrm{kg}$ TNT 


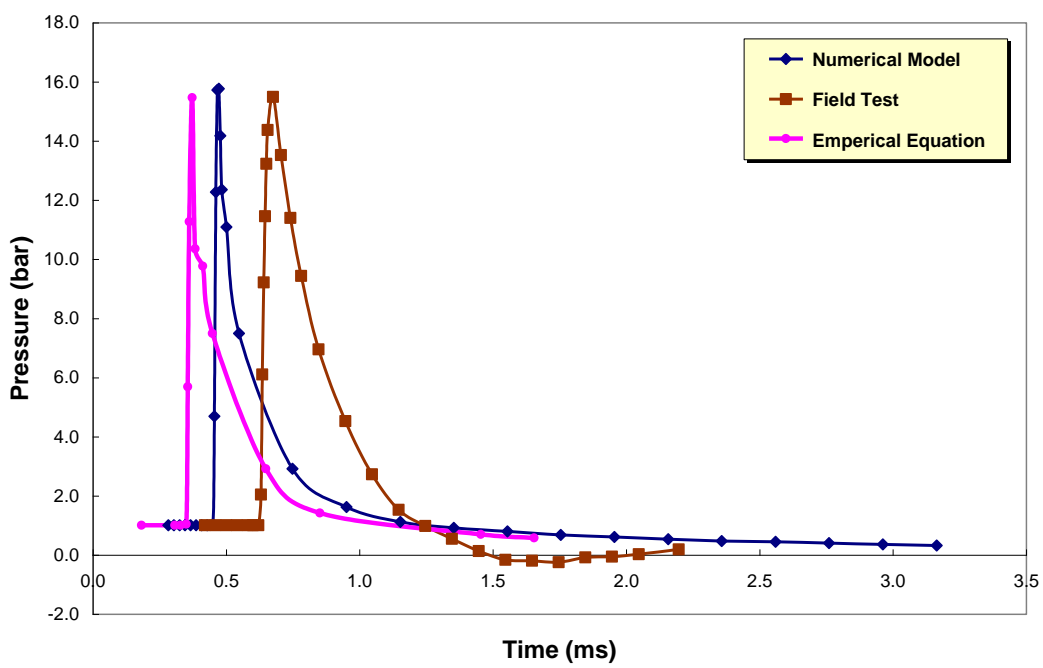

Fig. 9: Pressure-time history at point 1 for $2-\mathrm{kg}$ TNT

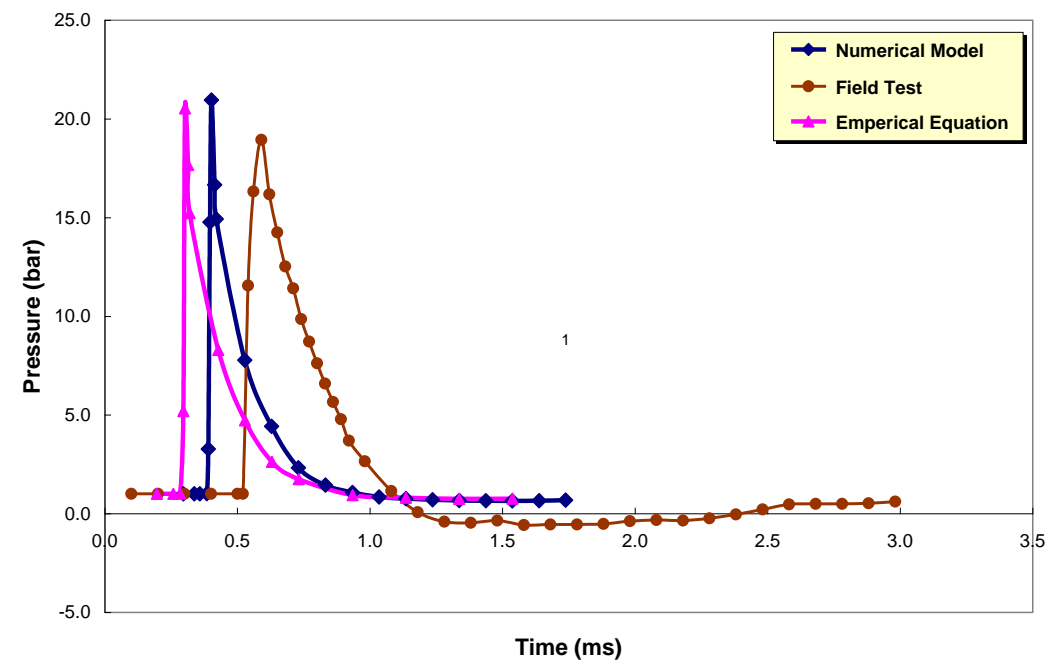

Fig. 10: Pressure-time history at point 1 for $3-\mathrm{kg}$ TNT

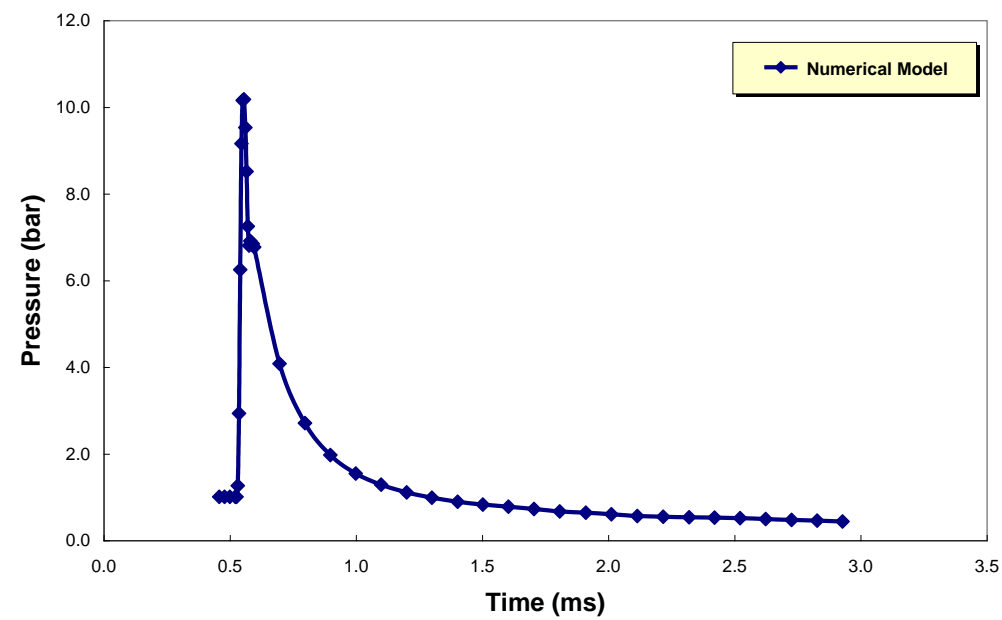

Fig. 11: Pressure-time history at point 1 for $1-\mathrm{kg}$ TNT 


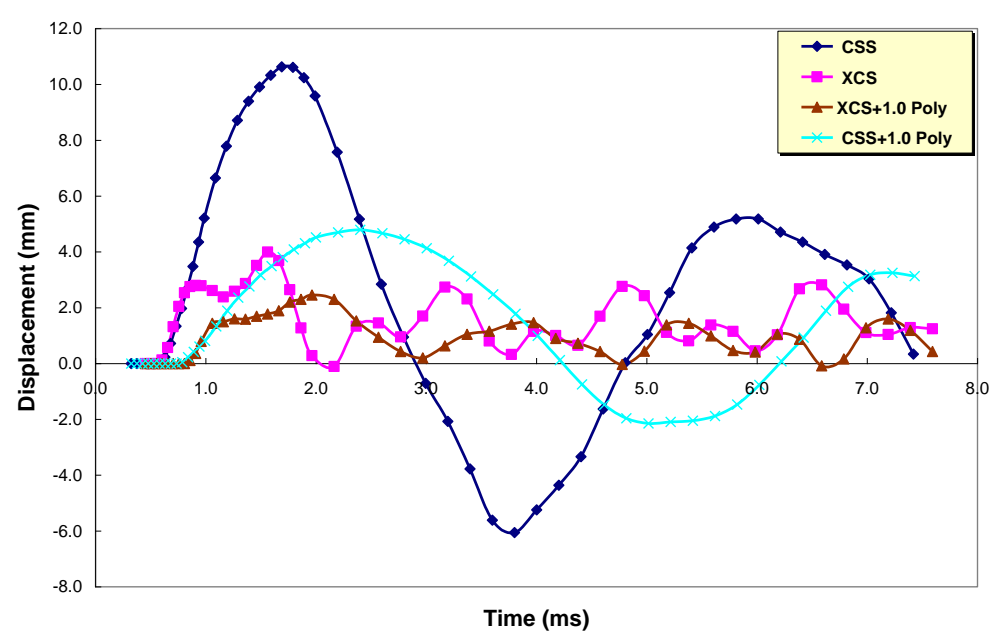

Fig. 12: Displacement - time history at point $1(1 \mathrm{~kg}$ TNT $)$

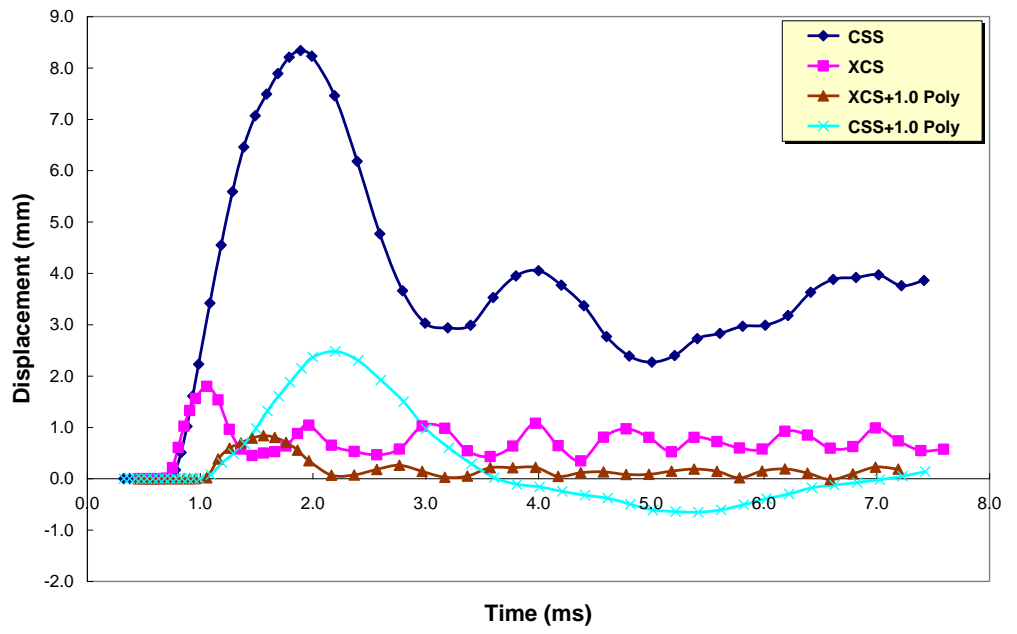

Fig. 13: Displacement - time History at point $2(1 \mathrm{~kg}$ TNT $)$

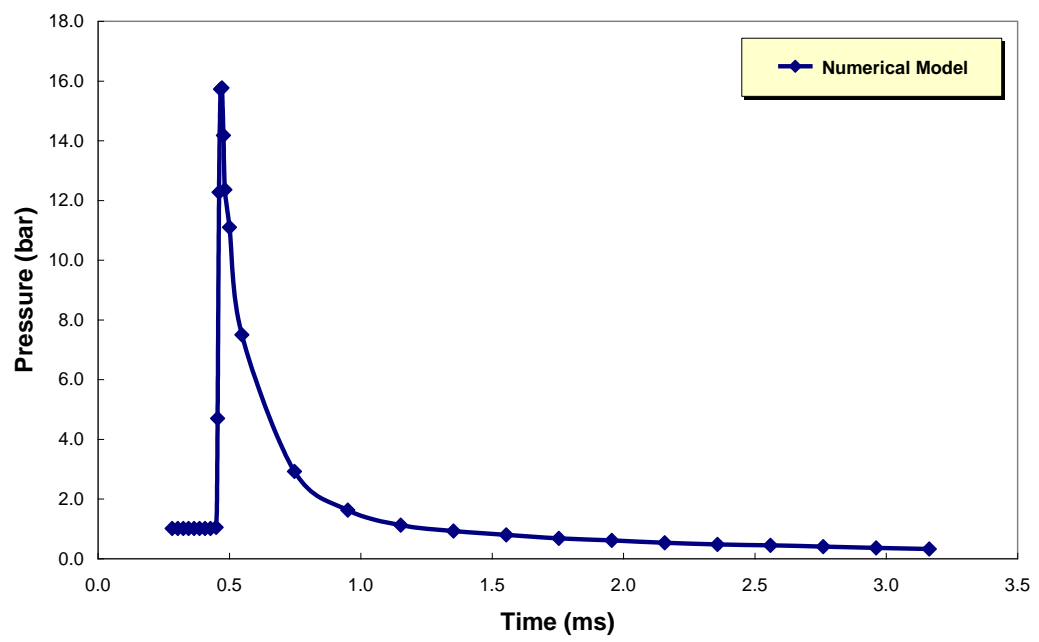

Fig. 14: Pressure-time history at point 1 for $2-k g$ TNT 


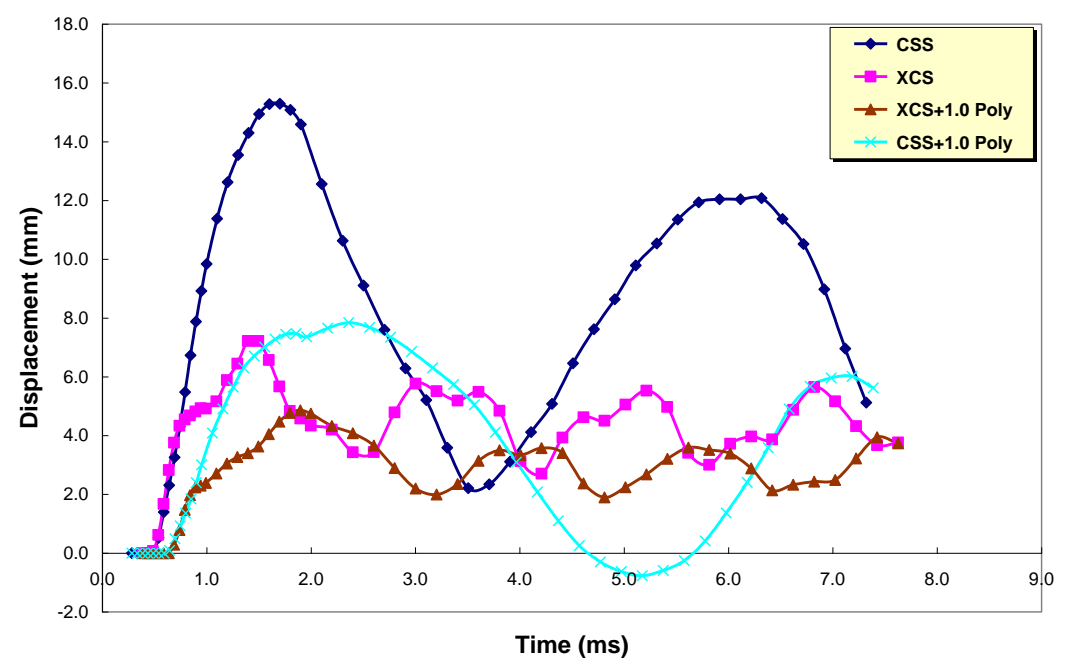

Fig. 15: Displacement - time history at point $1(2 \mathrm{~kg}$ TNT $)$

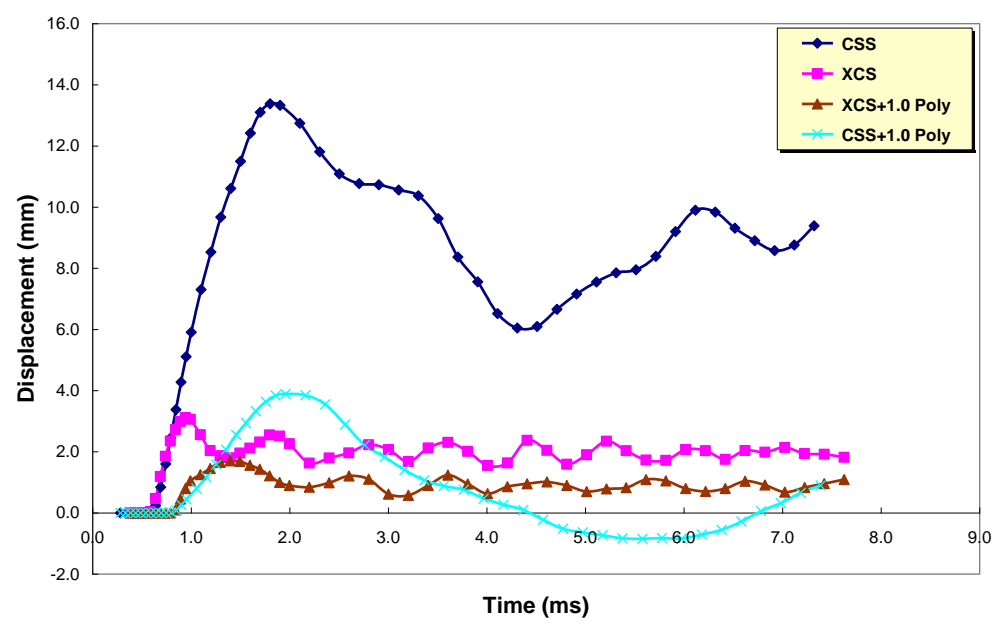

Fig. 16: Displacement - time History at point 2 (2 kg TNT) 


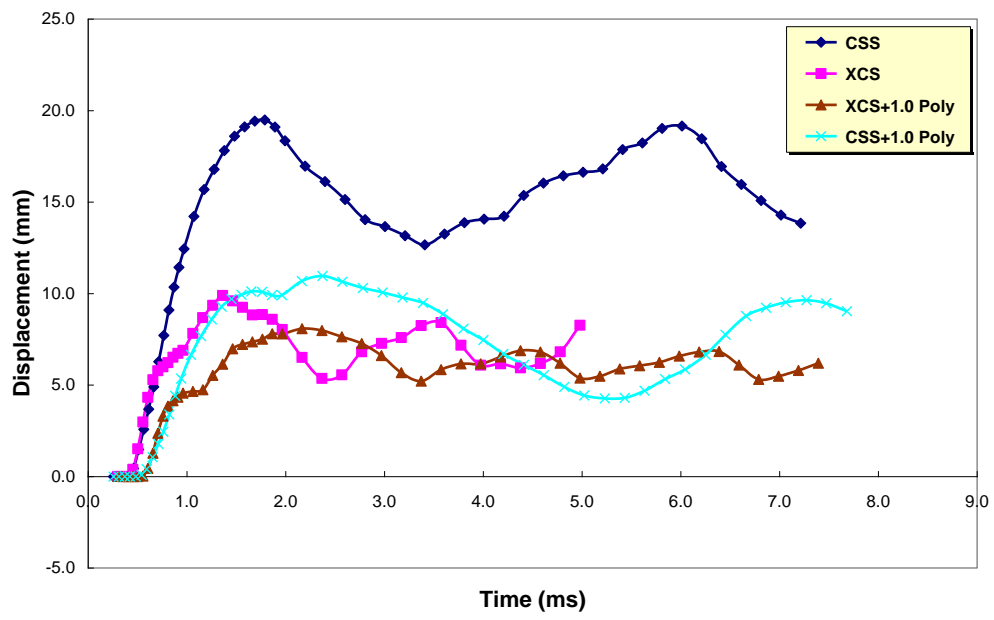

Fig. 17: Displacement - time history at point $1(3 \mathrm{~kg}$ TNT)

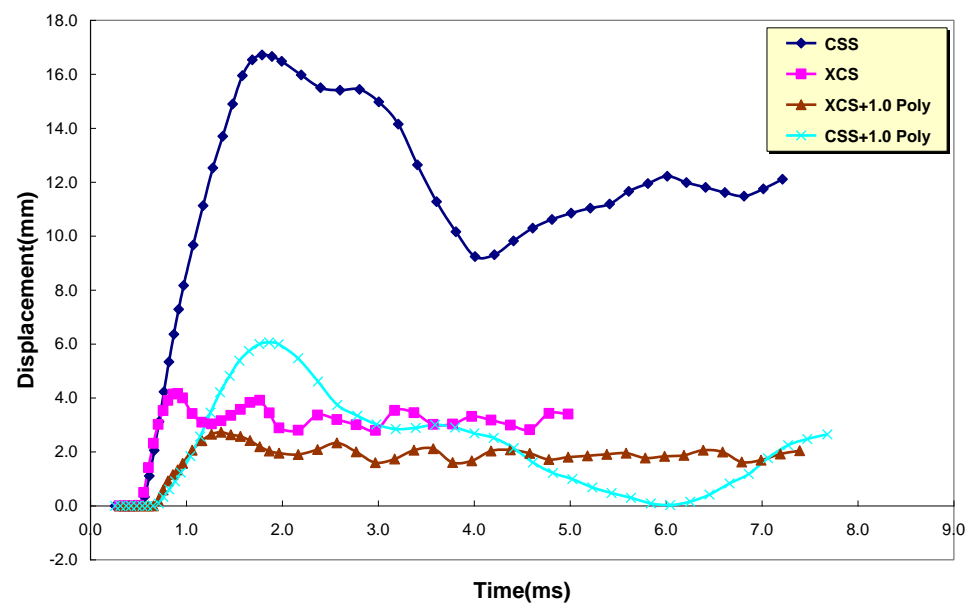

Fig. 18: Displacement - time history at point $2(3 \mathrm{~kg}$ TNT) 